\title{
Effects of Direct Focused Feedback and No Feedback on Run-on Sentences, Sentence Fragments, and Noun-pronoun Agreement Errors of EFL Tertiary Students
}

\author{
Jorge Villavicencio $^{1 *} \quad$ Juanita Argudo $^{2}$ \\ 1.Language Department, Universidad de Cuenca, 2-61 Nicanor Merchán Street, Bellavista 010101, Cuenca, \\ Ecuador \\ 2.La Estancia Street, San Joaquin 010163, Cuenca, Ecuador
}

\begin{abstract}
This quasi-experimental study set out to explore the effects of direct focused feedback and no feedback on runon sentences, sentence fragments, and noun-pronoun agreement errors in A2 writing tasks of EFL students at Universidad de Cuenca, Ecuador. The study comprised 39 participants divided into a treatment $(\mathrm{n}=20)$ and control group $(n=19)$. The feedback strategies were applied on 6 different tasks, and the first and last task were used as the pre- and posttest, respectively. After tallying the number of errors in the pre- and posttest, a statistical analysis was run. The results indicated that direct focused feedback, unlike the control group, produced significant changes in terms of run-on sentences and sentence fragments.
\end{abstract}

Keywords: direct focused, feedback, fragments, run-ons, noun-pronoun agreement, writing, EFL

DOI: $10.7176 / \mathrm{JEP} / 12-14-03$

Publication date:May $31^{\text {st }} 2021$

\section{Introduction}

It is known that acquiring a language is not an error-free process; on the contrary, errors are inevitable and present in the development of language skills. Writing, hence, is not an exception. In writing, a common concern stems from grammatical errors since they may cause communication failure (Sermsook, Liamnimitr \& Pockakorn, 2017), and this failure becomes even more evident in second language (L2) acquisition as L2 writing is certainly more challenging (Jodaie \& Farrokhi, 2012) and intimidating (Ministerio de Educación del Ecuador, 2016b, p. 15). Communicative failure due to grammatical errors is exemplified by Jodaie and Farrokhi (2012) as follows: She name is Mook meaning Her name is Mook.

Not only do grammar errors occur in writing but also in speaking (Touchie, 1986), so why is L2 writing worth analyzing and hopefully improving? First, development of writing, in the words of Nematzadeh and Siahpoosh (2017), is key in L2 development as learners have the opportunity to apply acquired language knowledge. Additionally, because writing serves academic and professional purposes (Ministerio de Educación del Ecuador, 2016b, p. 15), the Ministry of Education in Ecuador states that a task of teachers is to monitor the development of writing (2016a, p. 54). Bitchener and Ferris (2012), on their part, highlight the importance of writing as a means to validate whether learners are acquiring or not a target language. In this sense, teachers have an informative tool in their hands that serves to report to what extent grammar points have been mastered by students and to identify what needs adjustments. To illustrate this, after being informed on grammatical errors, teachers usually provide Written Corrective Feedback (WCF) to tell students what they need to improve.

Ferris (2010) calls for WCF as the means to make errors stand out for students in order to amend them; hence, avoiding error fossilization and allowing development of linguistic competence (Ferris, 2004). In fact, research evidence (Ferris, 2006; Hosseiny, 2014; Farshi \& Safa, 2015; Atmaca, 2016; Westmacott, 2017; Nematzadeh \& Siahpoosh, 2017; Wahyuni, 2017) shows that WCF has been used in its different strategies by teachers to correct written errors and help learners polish their writing skill. Despite the existence of studies presenting a positive impact by WCF, there are still opponents to error correction. Truscott (1996), as the main opponent, argues that WCF is ineffective and harmful because it can keep students from writing as they would prefer not making errors. Besides, he explains that ". . . research has found correction to be a clear and dramatic failure" (Truscott, 2007, p. 271). Based on these two sides, it is evident that there is still a debate whether WCF works or not.

Simultaneously, there is not a consensus on which feedback strategy may be the most effective. Sermsook et al. (2017) present direct feedback as one of the mostly debated strategies and insist on the need of further research in this realm. Direct feedback (DF) is defined as the replacement of an incorrect form (Saadi \& Saadat, 2015) for a corrected version by the teacher and deemed as a clear guide for error correction (Ellis, 2008). Some other studied strategies include indirect feedback and metalinguistic feedback. The former points out the existence of an error but does not correct it (Nematzadeh \& Siahpoosh, 2017) whereas the latter is a comment explaining the nature of an error (Ellis, 2008).

Equally important, there is a little amount of research related to feedback approaches, i.e. focused and 
unfocused feedback. Sheen, Wright and Moldawa (2009), Farrokhi and Sattapour (2012), and Kassim and Ng (2014) urge to gain more insights into these approaches by considering different grammatical targets. Moreover, Nematzadeh and Siahpoosh (2017) affirm that not many studies have been devoted to the analysis of the effects of focused feedback, so more evidence is needed. In terms of definition, focused feedback is the correction of specific error types whereas unfocused feedback is the correction of every error in a piece of writing (Ellis, Sheen, Muramaki \& Takashima, 2008).

In the case of Ecuador, the acquisition of English as a Foreign Language (EFL) is not an error-free process either as Chamba, Reinoso, and Rengifo (2019) recognize it. Ecuadorian EFL learners struggle with grammar in written productions as their pieces of work show errors related to both structure and form. As a matter of fact, in a Likert-type survey (see 3.2), teachers at the Language Department of Universidad de Cuenca acknowledged that students present grammatical inaccuracies which could eventually lead to communication breakdowns. It is known that, during staff meetings, teaching coordinators at the Language Department (LD) advise teachers to apply WCF in response to errors to enhance learners' grammatical accuracy as WCF is deemed as a useful tool for that purpose (Ferris, 2010). Following this, despite the fact that there is plenty of research on WCF, it is mainly focused on English as a Second Language (ESL) rather than EFL. In this respect, Westmacott (2017) highlights the existence of a big gap of WCF research in authentic EFL contexts. Indeed, after a quest on Repositorios de Acceso Abierto del Ecuador (RRAAE), only one unpublished Ecuadorian master's thesis by Escudero and Cundar (2016), partly focusing on the role of WCF, appeared in the database. Thereupon, teachers at the Language Department have no reference as to how WCF strategies could help in their context.

Having considered the aforementioned points, this study aims to explore the effects of direct focused feedback (DFF) and no feedback on run-on sentences, sentence fragments, and noun-pronoun agreement errors in A2 writing tasks of EFL students at Universidad de Cuenca. For this purpose, the following research questions were established:

1. What effects do direct focused feedback and no feedback have on run-on sentences, sentence fragments, and noun-pronoun agreement errors in A2 writing tasks of EFL students at Universidad de Cuenca?

2. To what extent are the effects of direct focused feedback and no feedback on run-on sentences, sentence fragments, and noun-pronoun agreement errors in A2 writing tasks of EFL students at Universidad de Cuenca different from each other?

\section{Literature Review}

\subsection{Written Corrective Feedback}

One fundamental practice of teachers is reacting to students' written tasks (Ferris, Pezone, Tade \& Tinti, 1997), and this reaction is generally carried out through WCF (Ferris, 2010). WCF allows teachers to comment on both content and form errors and provides students with a revision guide (Hashemenezhad \& Mohammadnejad, 2012). Further, Sheen and Ellis (2011) indicate that WCF serves for correcting written linguistic errors, and Almasi and Tabrizi (2016) reveal that feedback from either a teacher or peers is expected by students. Considering this, many studies have focused on the role of WCF in error correction and reported statistically significant improvements in student's grammar accuracy after its application (Ferris, 2006; Hosseiny, 2014; Farshi \& Safa, 2015; Alhumidi \& Uba, 2016; Westmacott, 2017; Nematzadeh \& Siahpoosh, 2017). Some of the studied targets have been the use of articles, copula 'be', prepositions, past tense, word choice, and subject-verb agreement. Accordingly, WCF has been considered an educational strategy to help learners correct their errors and polish their writing skills (Ferris, 2010).

Notwithstanding, there are some views against WCF. First, Salimi and Ahmadpour (2015) found that after the application of direct and indirect feedback at the intermediate level, a statistically significant difference between the pre and posttest did not occur. Nonetheless, there was accuracy improvement in the short term after comparing the means of the groups. Short-term effects are related to improvement from one draft to another whereas long-term effects refer to improved performance in new tasks (Ferris, 2006). Another study conducted by Wahyuni (2017) concluded that WCF did not have a significant impact on the grammatical accuracy of written productions of low-proficiency learners; however, the author recognized that the study had limitations like confusion when interpreting feedback and student's proficiency level, lack of time to solve students' doubts, and teacher's inexperience for teaching writing. Lastly, the main opponent of WCF, Truscott (1996), advocated for the inefficacy of WCF and determined that it is harmful for students as it may produce students' demotivation to keep writing as they would avoid making errors. In 2007, Truscott added that if there was any positive effect in WCF, it would be almost insignificant to be considered beneficial. Overall, WCF is considered a waste of time from Truscott's perspective.

As it is noted, evidence either in favor of or against the assistance of WCF in error correction is still inconclusive. 


\subsection{Studies on direct feedback and the focused approach}

Direct feedback is one of many strategies through which WCF can be applied, and several studies have focused on it by comparing it to other techniques like indirect, metalinguistic, or no feedback. Hashemnezhad and Mohammadnejad (2012) compared the impact of direct and indirect feedback on verb tense, prepositions, and relative pronouns of intermediate English-major students in Iran and found that both strategies were positive; however, the direct one fared significantly better than the indirect one in the long term. The researchers highlighted that WCF made finding errors easier for students.

In a similar line, Sarvestani and Pishkar (2015) concluded that the direct and indirect strategy had a positive impact on the accuracy of article use of intermediate learners. Based on the statistical analysis, they found significant differences between the two strategies and the no-feedback group in the long term, and DF presented itself as superior to the indirect type. Sarvestani and Pishkar (2015) endorsed that direct feedback was more effective since learners may not have enough knowledge to amend errors through indirect feedback. In the same year, Saadi and Saadat (2015) embarked to study the effects of direct and metalinguistic feedback on writing accuracy of 29 English-major students. Both strategies did not present any significant differences between them rather they produced positively similar changes. The authors assumed that when studies do not find effects in feedback provision is due to the lack of systematic provision. Finally, they suggested that feedback revision on the part of students is beneficial.

A work by Nguyen, Do, Nguyen, and Pham (2015) measured the impact of direct and metalinguistic feedback on the production and recognition of pragmatically appropriate email requests of 64 pre-service teachers taking intermediate writing classes in Vietnam. After a statistical analysis, the researchers pointed out that the effect produced on pragmatic accuracy by both feedback strategies was significantly equal and remarked that drafting and error revision aided learners to improve. Regardless of the students' level of pragmatic competence, WCF was beneficial as well. In the case of no-feedback provision, it had a negative effect as it prevented students from producing modified output. In terms of direct feedback, they stated that it allows students to notice correct forms and should be accompanied by revision. They also highlighted that direct feedback is less onerous for teachers and warned that the strategy does not permit us to know whether students understand the rules of a form or not.

In the line of focused feedback, Sheen et al. (2009) reached the conclusion that, combined with a direct strategy, the focused approach enhanced the use of articles of 80 intermediate ESL participants in both short and long terms unlike either no feedback or the unfocused approach applied to articles, copula 'be', regular and irregular past tense, third person 's', and prepositions. Sheen et al. (2009) stressed that having a focused approach benefits students as they center their attention on a specific range of errors whereas an unfocused approach does not allow students to process feedback effectively and could overwhelm them.

Partly agreeing on the previous findings, Farroki and Sattarpour (2011) asserted that direct focused feedback significantly improved article use of 60 high- and 60 low-proficiency learners and that the absence of feedback had no positive results. Unlike Sheen et al. (2009), Farroki and Sattarpour's (2011) results showed that direct unfocused feedback also had a positive impact but at a lower degree compared to the focused one. Aghajanloo, Mobini and Khosravi (2016), however, maintained that direct unfocused feedback performed statistically the best when compared to indirect unfocused, direct focused, and indirect focused feedback even though the others also had a beneficial impact. The strategies were applied to improve intermediate writing performance of 120 students in Iran.

Ellis et al. (2008), for their part, advocated that the focused and unfocused approach had the same positive effect as they significantly improved articled use in the long term whereas lack of feedback did not produce changes. Notwithstanding, Sheen et al. (2009) suggested that the lack of difference found in the study of Ellis et al.' (2008) was due to an unclear distinction between the approaches unlike their study. Both studies, however, agreed on the fact that the unfocused approach may not be useful for its wide range of corrections whereas a focused approach makes students better notice their inaccuracies on specific forms.

All in all, studies have yielded numerous results as to the efficacy of WCF strategies and approaches, so there is still a need of more insights into this field.

\section{Methodology \\ 3.1 Setting and Participants}

This quantitative study was conducted at the Language Department of Universidad de Cuenca, Ecuador, and had a quasi-experimental design involving two intact classes. Through semi-randomization, to compensate the lack of subject randomization (Macky \& Gass, 2005), one intact class was assigned as the treatment group ( $\mathrm{n}=20$ ) receiving direct focused feedback and the other class as the control group $(n=19)$ receiving no feedback. According to Bitchener and Ferris (2012), in order to effectively measure the impact of WCF, a control group that receives no feedback is required. The participants took English courses at the Department as part of their graduation requirements and belonged to majors such as Medicine, Engineering, Arts, and Law. They attended 
EFL classes 3 times a week for 2 hours each period during 4 months. The English proficiency level of the 39 Spanish-speaking participants was A2 based on the results obtained from the American English in Mind Placement Test (Putcha, Stranks, Lewis-Jones \& Carter, 2012).

\subsection{Choice of Targets Structures}

Ferris (2011) states that L2 writers can present errors related to punctuation, lexicon, and modification and the frequency of their occurrence may depend on learners' proficiency level and L1 influence. Hence, a Likert-type survey containing 8 grammatical errors was developed to find out which errors were commonly made by A2 students at the LD. Selecting the errors for the survey was based on the categories of treatable and untreatable errors by Ferris (2011) and the analysis of recurrent errors in 20 A2-writing tasks made by students at the Department. Additionally, the survey had a $9^{\text {th }}$ item which elicited written errors other than the listed ones but encountered by teachers. The survey was validated with 18 tertiary EFL teachers which suggested a few changes in terms of clarity of questions and error examples. The reliability of the survey was calculated by the Cronbach's alpha whose resulting coefficient was .76 indicating that the survey was reliable and could be used for collecting data. By using Google forms, 22 EFL teachers at the LD answered the survey, and the results determined that sentence fragments, noun-pronoun agreement, and run-on sentences were the top errors made by A2 students and could be the reason for communication breakdowns. Ferris (2011) acknowledges that teachers know which errors students make on a regular basis and could cause communication failures; therefore, the opinion of the teachers at the Department of Languages was taken into account. Interestingly, both the teachers at the LD and the teachers who were part of the piloting process mentioned already-listed errors in item $9^{\text {th }}$, so these answers were not considered.

\subsection{Instruments}

\subsubsection{The Placement Test}

Bitchener and Ferris (2012) maintain that, for WCF studies, it is fundamental that study groups have a homogenous L2 proficiency level; thus, to determine the participants' actual proficiency level, the American English in Mind Placement Test (Putcha et al., 2012) was applied. The test consists of 100 written multiplechoice questions focused on grammar points ranging from A1 to B2 level. Based on the test suggestions, 40 minutes were assigned to complete it.

\subsubsection{Writing Tasks}

The participants worked on 6 tasks of which the first and last one served as the pre- and posttest, respectively. Both the pre- and posttest were piloted with 20 students and 2 teachers-coworkers who provided feedback on clarity of instructions and/or spelling. The topics for the tasks were selected based on the class syllabus and the Cambridge International Exam KET for A2 level. The participants spent 60 minutes on writing each 180-word descriptive paragraph before submitting it. Bitchener and Ferris (2012) urge that the writing tasks should maintain the same writing genre throughout the tasks during WCF studies.

3.3.3 Tally sheets

The number of errors found in the pre- and posttest in the areas of run-on sentences, sentence fragments, and noun-pronoun agreement, were registered in Excel tally sheets for subsequent statistical procedures.

\subsection{Data Collection Procedure}

In order to carry out this study, four phases were followed:

Phase One:

First, two intact classes were selected as the study's groups. Then, the participants took the American English in Mind Placement Test (Putcha et al., 2012) to determine their actual L2 proficiency level. Only the participants whose L1 was Spanish and English level was A2 served as the subjects of the study. In total, 39 subjects were part of the treatment group $(n=20)$ and the control group $(n=19)$. Selecting which class served as the treatment group and which one as the control group was carried out through semi-randomization. In addition, as the study's targets were 3 specific grammatical errors, a focused approach was adopted. The application of DF strategy was as follows: right after an error was noticed by the teacher, it was crossed out and its correct form was provided above the error (Ellis, 2008; Saverstani \& Pishkar, 2015). In the case of the control group (CG), it did not receive specific feedback but general comments such as Good job! (Kassim \& Ng, 2014).

Phase Two:

The study's pretest was administered. The participants wrote a 180 -word descriptive paragraph in 60 minutes. As previously explained, the pretest was piloted with 20 other students and 2 teachers-coworkers. After students submitted the task, the class teacher provided DFF on run-ons, fragments, and noun-pronoun agreement. Then, the number of errors were tallied in Excel for a following statistical analysis to determine whether the treatment and the control group were in equal conditions. 
Phase Three:

A quick review on simple, compound, and complex sentences took place with the study's groups as the syllabus of the previous course did not devote enough time to review this topic unlike noun-pronoun agreement. Then, 4 non-piloted writing tasks, similar to the pre and posttest in structure but different in topic, were completed and excluded from the statistical analysis. Since the course syllabus should not be neglected as in the study of Almasi and Tabrizi (2016), both the syllabus content and activities were included. Hence, the procedure for each writing task including the pre- and the posttest was as follows: 1) followed by a short explanation of a grammar topic, a short video or passage of the class topic was presented, 2) followed by brainstorming, the writing task was given and explained to the participants to work in class, 3) after the participants submitted their paragraphs, DFF was applied to the treatment group whereas no feedback was for the control group, and 4) after returning the tasks, students had 15 minutes to check corrections. This revision stage is suggested by Ferris (2011) and has been employed in many studies (Ellis et al., 2008; Ferris \& Roberts, 2001; Sheen et al., 2009) as it is deemed as beneficial regardless of the WCF strategy used. It is worth mentioning that the 6 tasks were completed in 6 weeks; in other words, each task was completed in one class session of a week since the course syllabus, as previously explained, should not be neglected.

Phase Four:

Before applying the posttest, it was piloted with the same teachers and students that helped with the pretest. Then, it was administered and followed by feedback provision, tallying of errors, and the revision stage. Finally, statistical tests were run.

\subsection{Data Analysis Procedure}

SPSS version 25 was used to analyze the collected data. According to Bitchener and Ferris (2012), it is key to know the mastery level of students regarding the target structures to which feedback strategies are applied to accurately measure WCF impact. Hence, after tallying the number of errors of the target structures in the pretest, the Mann-Whitney-U test was run to determine the initial conditions of the groups. Then, a comparison between the results of the pre- and posttest of each group was made through the Wilcoxon signed-rank test to reveal if there were any significant differences produced by either DFF or CG. Finally, the Mann-Whitney-U test was used to determine if there were any significant differences between the effects of the strategies.

\section{Results}

To evaluate the conditions between DFF and the CG under the study's targets, the Mann-Whitney-U Test is used. Table 1 shows that the groups do not present significant differences $(\mathrm{p}>0.05)$ in run-ons, fragments, and nounpronoun agreement as their means and medians were similar. Hence, the groups are in equal conditions before the treatment.

Table 1. Results of the pretests

\begin{tabular}{|c|c|c|c|c|c|c|c|c|c|}
\hline & \multicolumn{6}{|c|}{ Group } & \multicolumn{3}{|c|}{ Test Statistics } \\
\hline & \multicolumn{3}{|c|}{$\begin{array}{c}\text { Direct Focused } \\
\text { Feedback }\end{array}$} & \multicolumn{3}{|c|}{ Control Group } & \multirow{2}{*}{$\begin{array}{c}\text { Mann- } \\
\text { Whitney U }\end{array}$} & \multirow{2}{*}{$\begin{array}{l}\text { Wilcoxon } \\
\text { W }\end{array}$} & \multirow{2}{*}{$\mathrm{p}$} \\
\hline & Mean & Median & SD & Mean & Median & SD & & & \\
\hline Run-on sentences & 5.1 & 5.0 & 1.7 & 5.1 & 5.0 & 1.3 & 184.500 & 394.500 & .879 \\
\hline Sentence Fragments & 1.6 & 1 & 1.6 & 1.4 & 1 & 1.6 & 181.000 & 371.000 & .813 \\
\hline $\begin{array}{l}\text { Noun-pronoun } \\
\text { agreement }\end{array}$ & .5 & .0 & .7 & .3 & .0 & .7 & 157.500 & 347.500 & .365 \\
\hline
\end{tabular}

4.1 Investigation of Research Question 1

To assess the impact of DFF and the CG on sentence fragments, run-on sentences, and noun-pronoun agreement errors, a comparison between the pretest and posttest of each group is made. Table 2 shows that DFF produced significant changes $(\mathrm{p}<.05)$ in the categories of run-ons and fragments as there are several cases of error decrease. However, in the category of noun-pronoun agreement, no significant changes ( $p>05)$ result as 12 participants make the same number of errors in both the pre- and posttest.

Table 2. Comparison of the pretest and posttest: Direct Focused Feedback

\begin{tabular}{lccc}
\hline \multicolumn{1}{c}{ Changes } & Run-on sentences & Sentence fragments & Noun-pronoun agreement \\
\hline Decrease & 16 & 10 & 5 \\
Increase & 3 & 2 & 3 \\
Tie & 1 & 8 & 12 \\
$\mathrm{p}$ & .001 & .011 & .470 \\
\hline
\end{tabular}

Table 3 shows that the CG does not produce significant changes in the category of run-ons $(p>.05)$ despite 10 error-decrease cases. With regard to sentence fragments and noun-pronoun agreement, several participants 
maintain the same number of errors in both the pre- and posttest, resulting in no significant changes ( $\mathrm{p}>.05)$.

Table 3. Comparison of the pretest and posttest: Control Group

\begin{tabular}{lccc}
\hline \multicolumn{1}{c}{ Changes } & Run-on sentences & Sentence fragments & Noun-pronoun agreement \\
\hline Decrease & 10 & 3 & 3 \\
Increase & 4 & 8 & 1 \\
Tie & 5 & 8 & 15 \\
$\mathrm{p}$ & .070 & .241 & .450 \\
\hline
\end{tabular}

\subsection{Investigation of Research Question 2}

To investigate the existence of differences or similarities between the two study groups, the changes between the pre- and posttest are compared. Table 4 shows that there are significant differences $(p<.05)$ between the DFF group and the $\mathrm{CG}$ in terms of run-ons and sentence fragments, favoring the former group. Additionally, the CG participants regress in the area of fragments (mean=.4). Regarding noun-pronoun agreement, the existing changes in the groups are not significantly different $(\mathrm{p}>.05)$.

Table 4. Comparison of the differences between the pre and posttest of the groups

\begin{tabular}{|c|c|c|c|c|c|c|c|c|c|}
\hline & \multicolumn{6}{|c|}{ Group } & \multicolumn{3}{|c|}{ Test Statistics } \\
\hline & \multicolumn{3}{|c|}{$\begin{array}{l}\text { Direct Focused } \\
\text { Feedback }\end{array}$} & \multicolumn{3}{|c|}{ Control Group } & \multirow{2}{*}{$\begin{array}{c}\text { Mann- } \\
\text { Whitney U }\end{array}$} & \multirow{2}{*}{$\begin{array}{c}\text { Wilcoxon } \\
\text { W }\end{array}$} & \multirow{2}{*}{$\mathrm{p}$} \\
\hline & Mean & Median & SD & Mean & Median & $\mathrm{SD}$ & & & \\
\hline $\begin{array}{l}\text { Posttest - Pretest } \\
\text { (Run-on sentences) }\end{array}$ & -2.8 & -3.0 & 2.5 & -1.1 & -2.0 & 2.5 & 109,000 & 319,000 & .022 \\
\hline $\begin{array}{l}\text { Posttest - Pretest } \\
\text { (Sentence Fragments) }\end{array}$ & -1.1 & -.5 & 1.7 & .4 & .0 & 1.5 & 95,500 & 305,500 & .007 \\
\hline $\begin{array}{l}\text { Posttest - Pretest } \\
\text { (Noun-pronoun } \\
\text { agreement) }\end{array}$ & -.2 & .0 & .9 & -.2 & .0 & .8 & 190,000 & 380,000 & 1.0 \\
\hline
\end{tabular}

Finally, the results of the posttests of both groups are compared to find any existent differences or similarities. Table 5 shows that DFF fare significantly better $(p<.05)$ than the CG in the categories of run-ons and fragments which confirms the outcomes found in Table 4. In terms of noun-pronoun agreement, the groups do not present any significant difference $(\mathrm{p}>.05)$.

Table 5. Comparison of the posttests

\begin{tabular}{|c|c|c|c|c|c|c|c|c|c|}
\hline & \multicolumn{6}{|c|}{ Group } & \multicolumn{3}{|c|}{ Test Statistics } \\
\hline & \multicolumn{3}{|c|}{$\begin{array}{c}\text { Direct Focused } \\
\text { Feedback } \\
\end{array}$} & \multicolumn{3}{|c|}{ Control Group } & \multirow{2}{*}{$\begin{array}{c}\text { Mann- } \\
\text { Whitney U }\end{array}$} & \multirow{2}{*}{$\begin{array}{l}\text { Wilcoxon } \\
\text { W }\end{array}$} & \multirow{2}{*}{$\mathrm{p}$} \\
\hline & Mean & Median & $\mathrm{SD}$ & Mean & Median & SD & & & \\
\hline Run-on sentences & 2.3 & 2 & 2.1 & 4 & 4 & 1.9 & 100.500 & 310.500 & .011 \\
\hline Sentence Fragments & .5 & 0 & .8 & 1.8 & 2 & 0 & 82.000 & 292.000 & .002 \\
\hline $\begin{array}{l}\text { Noun-pronoun } \\
\text { agreement }\end{array}$ & .3 & 0 & .6 & .1 & 2 & .5 & 154.500 & 344.500 & .322 \\
\hline
\end{tabular}

\section{Discussion}

Considering the results of the statistical tests, the research questions can be answered now.

\subsection{Addressing research question 1}

The statistical results showed that direct focused feedback positively aided learners to improve their grammatical errors, specifically in the areas of run-ons and sentence fragments. On the contrary, the analysis of the control group yielded negative results as participants did not improve.

On the one hand, it seems that Written Corrective Feedback has a beneficial impact on correcting errors based on the previous results. This is in line with the findings of different studies (Ferris, 2006; Hosseiny, 2014; Farshi \& Safa, 2015; Alhumidi \& Uba, 2016) that have concluded that grammar accuracy in writing can be improved through the application of WCF. Specially, DFF was advantageous for students as they were able to amend their errors; fact that is in accordance with the findings of Nguyen et al. (2015) and Sarvestani and Pishkar (2015). The positive effect of DFF as a WCF strategy may be thanks to its role as an error map since it clearly presents errors to students. Hashemenezhad and Mohammadnejad (2012), in this regard, state that one of the roles of WCF is of a revision guide, and Ellis (2008) identifies DF as a clear guide for students while working on error correction. Additionally, the use of a focused approach appears to be useful to help students improve their grammatical accuracy as reported in this and other studies conducted by Sheen et al. (2009) and Aghajanloo et al. (2016). Apparently, the benefits emerge because of the limited number of errors the approach 
works with which makes students better focus on errors. In fact, Sheen et al. (2009) concede that a focused approach benefits students as they center their attention on a specific range of errors.

On the other hand, absence of feedback provision might cause unwanted effects like regression which was evinced in the category of sentence fragments. Lack of improvement may be due to the fact that students did not know which grammatical structures were faulty. Ferris (2010) remarks that in order to improve grammatical accuracy, students should have their errors made salient; task that can be completed through WCF. Finally, the findings regarding lack of feedback are opposite to Truscott's (2007) position which argues that if WCF could produce any effect, it would be insignificant to be considered useful.

\subsection{Addressing research question 2}

The results indicated that there were significant differences between the effects of DFF and lack of feedback, favoring the former group in the areas of run-ons and fragments. These outcomes are in good agreement with the studies of Farroki and Sattarpour (2011), Saverstani and Pishkar (2015), and Nguyen et al. (2015).

Hashemenezhad and Mohammadnejad (2012) and Saverstani and Pishkar (2015) remark that the measured effects of the direct strategy are positive in the long run. Interestingly, the findings of this study coincide with those reports. The long-term impact might be the result of spending time on revising errors on the part of students. Indeed, Saadi and Saadat (2015) comment that feedback revision is beneficial and Nguyen et al. (2015) suggest it as an accompanying tool of direct feedback to improve. Furthermore, direct feedback positively aided low-proficiency students to improve their grammatical accuracy, and this is supported by Farroki and Sattarpour (2011) who found benefits of the strategy at a low language level as well. Additionally, Sarvestani and Pishkar (2015) acknowledge that DF is appropriate for low levels as these learners may not have sufficient linguistic knowledge to correct errors independently.

Along with other studies (Sheen et al., 2009; Saverstani \& Pishkar, 2015) that found no benefit in the absence of feedback provision, Nguyen et al. (2015) argue that lack of feedback prevented students from producing modified output, and this corroborates the findings of this study as the participants did not improve their grammatical accuracy. Seemingly, when errors are not pointed out, students do not know what to correct. In other words, they ignore what they need to improve. Ferris (2010) sees in WCF a tool to make errors salient so that students develop their linguistic competence (Ferris, 2004).

In the case of noun-pronoun agreement errors, there were no significant changes to be reported in either group. The lack of effects in feedback provision may be due to the small number of errors students made in the pretest. Although teachers at the Language Department, based on their experience with past class groups, identified this category as common among students, the treatment group did not present serious issues. Ferris (2011) maintains that "not all students make the same types of errors" (p. 85); hence, it seems plausible to say that teachers should not generalize a type of error from group to group although the learners belong to the same context.

\section{Conclusions}

This study aimed to examine the effects of direct focused feedback and no-feedback provision on the correction of run-on sentences, sentence fragments, and noun-pronoun agreement errors, and it was found that feedback provision was statistically positive. Based on this, it seems reasonable to suggest the application of direct feedback along with a focused approach to address common errors among L2 learners. Consequently, devoting time to this task can be a helpful tool for teachers to work on error correction. Additionally, it is recommended that teachers have students revise their errors so that they can notice them, correct them, and hopefully, learn their correct forms. Nevertheless, the results of the study should be interpreted with caution since there were some limitations. First, the number of participants is of a small size, so a study with larger number is suggested. Second, the results were found in three specific targets, so further analysis of WCF impact on both these targets and other structures is highly recommended. Similarly, further research in the area of the focused approach is still needed. Finally, the obtained results are applicable to only the employed sample with its specific characteristics, so results cannot be generalized to other populations.

\section{References}

Aghajanloo, K., Mobini, F., \& Khosravi, R. (2016). The effect of teachers' written corrective feedback (WCF) types on intermediate EFL learners' writing performance. Advances in Language and Literary Studies, 7(3), 28-37. Doi:10.7575/aiac.alls.v.7n.3p.28

Alhumidi, H. A., \& Uba, S. Y. (2016). The effect of indirect written corrective feedback to Arabic language intermediate students' in Kuwait. European Scientific Journal, 12(28), 361-373. Doi: 10.19004/esj.2016.v12n28p361

Almasi, E., \& Tabrizi, A. R. N. (2016). The effects of direct vs. indirect corrective feedback on iranian EFL learners' writing accuracy. Journal of Applied Linguistics and Language Research, 3(1), 74-85. 
Atmaca, Ç. (2016). Contrasting perceptions of students and teachers: written corrective feedback. Journal of Language and Linguistic Studies, 12 (2), 166-182.

Bitchener, J. \& Ferris, D. (2012). Written Corrective Feedback in Second Language Acquisition and Writing. New York, NY: Routledge.

Chamba, M., Reinoso, M., \& Rengifo, E. (2019). Authentic Materials to Foster Writing Skills in College EFL Learners. English Language Teaching, 12(6), 112-127.

Ellis, R. (2008). A typology of written corrective feedback types. ELT journal, 63(2), 97-107.

Ellis, R., Sheen, Y., Murakami, M., \& Takashima, H. (2008). The effects of focused and unfocused. System, 36, 353-371. Doi:10.1016/j.system.2008.02.001

Escudero Orozco, G. I., \& Cundar, A. (2016). Elaboration and implementation of the meaningful learning assessment guide "Beside" to build up academic reading and writing skills in English as a foreign language in the students of the seventh semester of the medicine school at the National University of Chimborazo in the school year 2014-2015. (Master's dissertation). Retrieved from http://dspace.unach.edu.ec/handle/51000/2753

Farrokhi, F., \& Sattarpour, S. (2011). The Effects of Focused and Unfocused Written Corrective Feedback on Grammatical Accuracy of Iranian EFL Learners. Theory \& Practice in Language Studies, 1(12), 1797-1803. Doi: $10.4304 /$ tpls.1.12.1797-1803

Farrokhi, F., \& Sattarpour, S. (2012). The effects of direct written corrective feedback on improvement of grammatical accuracy of high-proficiency L2 learners. World Journal of Education, 2(2), 49-55. Doi:10.5430/wje.v2n2p49

Farshi, S. S., \& Safa, S. K. (2015). The effect of two types of corrective feedback on EFL learners' writing skill. Advances in Language and Literary Studies, 6(1), 26-30.

Ferris, D. (2004). The 'grammar correction' debate in L2 writing: Where are we, and where do we go from here? (and what to do in the meantime...?). Journal of Second Language Writing, 13, 49-62. Doi:10.1016/j.jslw.2004.04.005

Ferris, D. (2006). 'Does error feedback help student writers? New evidence on the short and long-term effects of written error correction. In K. Hyland \& F. Hyland (Eds.), Feedback in second language writing: Contexts and issues (pp. 81-104). Cambridge, U.K.: Cambridge University Press.

Ferris, D. (2010). Second language writing research and written corrective feedback in SLA: Intersections and practical applications. Studies in Second Language Acquisition, 32, 191-201. Doi:10.1017/S0272263109990490

Ferris, D. (2011). Treatment of error in second language student writing. Michigan, MI: University of Michigan.

Ferris, D., Pezone, S. Tade, C., \& Tinti, S. (1997). Teacher commentary on student writing: Descriptions and implications. Journal of Second Language Writing, 6, 155-182.

Ferris, D., \& Roberts, B. (2001). Error feedback in L2 writing classes: How explicit does it need to be? Journal of Second Language Writing, 10, 161-184. Doi:10.1016/S1060-3743(01)00039-X

Hashemnezhad, H. \& Mohammadnejad, S. (2012). A case for direct and indirect feedback: The other side of coin. English Language Teaching, 5(3), 230-239. Doi:10.5539/elt.v5n3p230

Hosseiny, M. (2014). The role of direct and indirect written corrective feedback in improving Iranian EFL students' writing skill. Procedia-Social and Behavioral Sciences, 98, 668-674. Doi:10.1016/j.sbspro.2014.03.466

Jodaie, M. \& Farrokhi, F. (2012). An exploration of private language institute teachers' perceptions of written grammar feedback in EFL classes. English Language Teaching, 5(2), 58-67. Doi:10.5539/elt.v5n2p58

Kassim, A. \& Ng, L. (2014). Investigating the efficacy of focused and unfocused corrective feedback on the accurate use of prepositions in written work. English Language Teaching, 7(2), 119-130. Doi:10.5539/elt.v7n2p119

Mackey, A., \& Gass, S. M. (2005). Second Language Research: Methodology and Design. Mahwah, NJ: Lawrence Erlbaum Associates, Inc.

Ministerio de Educación del Ecuador $\left(2016^{\mathrm{a}}\right)$. English as a foreign language for subnivel superior: educación general básica. Retrieved from: https://educacion.gob.ec/ curriculo-lengua-extranjera/

Ministerio de Educación del Ecuador (2016b). English as a foreign language: educación general básica elemental. Retrieved from: https://educacion.gob.ec/curriculo-lengua-extranjera/

Nematzadeh, F. \& Siahpoosh, H. (2017). The effect of teacher direct and indirect feedback on Iranian intermediate EFL learners' written performance. Journal of Applied Linguistics and Language Learning, 3(5), 110-116. Doi:10.5923/j.jalll.20170305.02

Nguyen, T. T. M., Do, T. T. H., Nguyen, A. T., \& Pham, T. T. T. (2015). Teaching email requests in the academic context: a focus on the role of corrective feedback. Language Awareness, 24(2), 169-195. Doi:10.1080/09658416.2015.1010543

Puchta, H., Stranks, J., Lewis-Jones, P. \& Carter, R. (2012). American English in Mind Placement Test. 
Retrieved from http://www.cambridge.org/files/3113/8071/0235/ american-english-in-mind-placementtests-written-test.pdf

Saadi, Z. \& Saadat, M. (2015). Iranian EFL learners' grammatical knowledge: effect of direct and metalinguistic corrective feedback. English Language Teaching, 8(8), 112-120. Doi:10.5539/elt.v8n8p112

Salimi, A., \& Ahmadpour, M. (2015). Ehe effect of direct vs. indirect written corrective feedback on L2 learners written accuracy in EFL context. International Journal of English Language and Literature Studies, 4(1), 10-19.

Sarvestani, M. S., \& Pishkar, K. (2015). The effect of written corrective feedback on writing accuracy of intermediate learners. Theory and Practice in Language Studies, 5(10), 2046-2052.

Sermsook, K., Liamnimitr, J. \& Pochakorn, R. (2017). The impact of teacher corrective feedback on EFL student writers' grammatical improvement. English Language Teaching, 10(10), 43-49. Doi: 10.5539/elt.v10n10p43

Sheen, Y., Wright, D., \& Moldawa, A. (2009). Differential effects of focused and unfocused written correction on the accurate use of grammatical forms by adults ESL learners. System, 37, 556-569. Doi:10.1016/j.system.2008.02.001

Sheen, Y., \& Ellis, R. (2011). Corrective feedback in language teaching. In E. Hinkle (Ed.), Handbook of research in second language teaching and learning (pp. 593-609). New York: Taylor \& Francis.

Touchie, H. Y. (1986). Second language learning errors: their types, causes, and treatment. JALT Journal, 8(1), $75-80$.

Truscott, J. (1996). The case against grammar correction in L2 writing classes. Language Learning, 46, 327-369. Doi:10.1111/j.1467-1770.1996.tb01238.x

Truscott, J. (2007). The effect of error correction on learners' ability to write accurately. Journal of Second Language Writing, 16(4), 255-272. Doi:10.1016/j.jslw.2007.06.003

Wahyuni, S. (2017). The effect of different feedback on writing quality of college students with different cognitive styles. Dinamika Ilmu, 17(1), 39-58. Doi:10.21093/di.v17i1.649

Westmacott, A. (2017). Direct vs. indirect written corrective feedback: student perceptions. Ikala, 22(1), 17-32. Doi:10.17533/udea.ikala.v22n01a02 